\title{
Eating attitudes and barriers to healthy eating and physical activity among a sample of university students in Egypt
}

\section{Original Article}

\author{
Lamyaa S. El-Bagoury, Azza M. Hassan, Hasnaa A. AbouSeif
}

Department of Community, Environmental and Occupational Medicine, Faculty of Medicine, Ain Shams University, Cairo, Egypt

\begin{abstract}
Background: More students are concerned about their body shape and have a desire to have a lower BMI. As a consequence, many of them have disordered eating attitudes (DEAs) and engage themselves in unhealthy weight control behaviors.

Aim: To measure the frequency of DEAs among Ain Shams University students and to identify the barriers to healthy eating and physical activity among them.

Materials and Methods: A cross-sectional study was done on a sample of 445 students in Ain Shams University from different faculties using a self-reported questionnaire. The weight and height were measured and the BMI was calculated. The eating attitudes were measured using the Eating Attitudes Test-26 questionnaire.

Results: The students' age ranged between 17 and 26 years with a mean of $20.3 \pm 1.5$ years, $40.7 \%$ of them were men and $59.3 \%$ women. The majority of students $(50.8 \%)$ had normal BMI, and about $39 \%$ were overweight and obese. The frequency of DEAs was $73.3 \%$. There was no significant relation between the presence of DEAs and personal data of students such as age, sex, faculty, and BMI. Lack of time was the most highlighted barrier to both physical activity and healthy eating.

Conclusion: There was a high prevalence rate of obesity and DEA that necessitates a lot of efforts to help the youth control their body weights and correct unhealthy behaviors by overcoming barriers against healthy behaviors.
\end{abstract}

Received: 19 November 2016, Accepted: 04 March 2017

Key Words: Barriers, BMI, eating attitudes test, obesity, physical activity.

Corresponding Author: Hasnaa A. AbouSeif, MD, Department of Community, Environmental and Occupational Medicine, Faculty of Medicine, Ain Shams University, Cairo, Egypt, Tel.: +20 111193 6951, E-mail: drhasnaaabouseif@yahoo.com.

ISSN: 0013-2446, Vol. 92, No.1

\section{INTRODUCTION}

Disordered eating attitudes (DEAs), especially among adolescents and young women, have become an important issue worldwide ${ }^{[1]}$. University students are in the emerging adulthood period which is a critical time during which young people establish independence and adopt life-long patterns of health and behavior. It is the time associated with unhealthy lifestyle characteristics and increased risk of obesity and chronic diseases ${ }^{[2,3]}$. The transition to college life often worsens dietary habits among students, as this is the period during which individuals are for the most part exposed to lack of time and stress which is associated with poor diets and inactivity ${ }^{[3,4]}$.

There are many social, cultural, and psychological factors associated with eating attitudes and behaviors. Cultural transition, social changes, westernization, family environment, exposure to mass media, and globalization all have a significant impact on eating attitudes and behaviors, especially among young people ${ }^{[5]}$.
The prevalence of eating disorders (EDs) has increased markedly during the recent decades in both developing and developed countries, especially among young people. It was reported that the proportion of EDs among children and adolescents in western countries is higher than that of type 1 diabetes $^{[6,7]}$.

According to the American Psychological Association ${ }^{[8]}$ EDs can be defined as abnormal eating habits that can threaten people's health or even life. They include anorexia nervosa, bulimia nervosa, and binge eating. EDs have serious health consequences that affect a person's emotional, productivity, relationship, and physical health ${ }^{[6]}$.

Previous studies about barriers to healthy eating and physical activity showed that the most frequently reported barriers to healthy eating were the lack of time and stress, which is associated with poor diets and inactivity ${ }^{[9]}$, convenience and lower cost of less nutritious fast food $^{[10]}$, lack of availability and high cost of healthier food $^{[11]}$, taste preferences (e.g. for fast foods) and lack of 
nutrition knowledge and skills ${ }^{[12]}$. Reported barriers to practicing physical activity in previous studies were time constraints, lack of motivation, inadequate sport facilities and equipment, lack of energy, lack of self-discipline, discomfort, cost, lack of family and friends' support, illness and injury ${ }^{[13]}$.

In spite of the high rates of obesity and DEAs among university students, studies on barriers to the adoption of healthy eating and a healthy lifestyle in university students in Arab counties are to some extent lacking. Understanding barriers to a healthy lifestyle is important for planning targeted interventions to promote the nutritional and health status of university students. The objectives of this study are to measure the frequency of DEAs among Ain Shams University students and to identify the barriers to healthy eating and physical activity among them.

\section{MATERIALS AND METHODS}

\section{Participants and sampling}

This cross-sectional study was done on students of Ain Shams University from different faculties such as Medicine, Commerce, Arts, and Law during the academic year 2015-2016. Data were collected between November 2015 and January 2016.

\section{Sample size}

A minimum sample of 385 students was considered adequate assuming that the proportion of students with $\mathrm{DEA}=50 \pm 5 \%$ at $95 \%$ confidence interval using Epi Info 7 Program, Centers for Disease Control and Prevention, USA. The number was raised to compensate for nonresponse and missing data and the ultimate number was 445 students. A convenient sample was obtained from the medical and nonmedical faculties in the university.

\section{Study tool}

(1) A self-administered questionnaire was used to collect student's personal data and barriers to healthy eating and physical activity. Statements of these barriers were obtained from a previously published study done in seven Arab countries (Algeria, Jordan, Kuwait, Libya, Palestine, Syria, and the United Arab Emirates) to identify the perceived personal, social, and environmental barriers to healthy eating and physical activity among Arab adolescents $^{[14]}$. Slight modifications were then carried out to adapt the statements to the Egyptian culture as well as to the target group of this study (university students). The final version of the questionnaire consisted of 10 and 14 statements that were related to barriers to healthy eating and to physical activity, respectively. The barriers were divided into personal, social, and environmental barriers. Response options for all the barriers statements were not a barrier, a somewhat important barrier, and a very important barrier.

(2) The Eating Attitudes Test (EAT-26) was used to measure those at risk of DEAs ${ }^{[15]}$. The EAT-26 has been validated and used in several countries and among various age groups. In this study, we used the Arabic version of EAT-26, which was validated by Al-Subaie $\boldsymbol{e t}$ al. ${ }^{[16]}$, and used among adolescents aged between 12 and 18 years and women in some Arab countries such as Egypt ${ }^{[17]}$, Saudi Arabia $^{[18]}$, and the United Arab Emirates ${ }^{[19]}$. The EAT26 consists of 26 statements referring to various eating attitudes. Each statement uses a six-point Likert-type scale ranging from 'always' to 'never'. A score of three points was given for 'always', two for 'usually', one for 'often' and none for 'sometimes', 'rarely' and 'never'. The participant was considered at risk of DEAs and behaviors when the total score was 20 points or above. The EAT26 assesses a broad range of symptoms such as dieting, eating attitudes, weight concern, binge eating, anorexia, and bulimia.

(3) Anthropometric measurements: Body weight was measured to the nearest $100 \mathrm{~g}$ with calibrated portable scales with minimal clothing and without shoes. Height was measured to the nearest centimeter with a calibrated measuring rod while the subject was in full standing position without shoes. BMI was calculated as the body weight in kilograms divided by the square of the body height in meter, and expressed in units of $\mathrm{kg} / \mathrm{m} 2$.

BMI was further classified into:

- A BMI of less than 18.5 is considered as underweight.

- A BMI of 25.0-29.9 is overweight.

- A BMI of 30.0 or higher is obese ${ }^{[20]}$.

\section{Statistical analysis}

Data were analyzed using statistical package for the social sciences (SPSS) program version 18 (released 2009, PASW statistics for Windows, version 18.0; SPSS Inc., Chicago, Illinois, USA).

To describe the studied sample, quantitative data such as age were presented as minimum, maximum, mean, and as SD. Qualitative data such as sex were presented as count and percentage. Independent samples t-test was used to compare age between two groups of DEA and non-DEAs and $\chi^{2}$-test was used to compare sex and BMI between them. A P value of less than 0.05 was considered statistically significant.

\section{Ethical considerations}

Informed consent was obtained from the students after explaining the purpose of the study. The students were informed about their anthropometric measurements and confidentiality of data was ensured.

\section{RESULTS}

The personal data of 445 studied students are presented in Table 1. Their age ranged between 17 and 26 years with a mean of $20.3 \pm 1.5$ years, $40.7 \%$ of them were men and $59.3 \%$ were women; $22.7 \%$ of students were from faculty of medicine and the others $(77.3 \%)$ were from different faculties like Commerce, Laws, and Arts. The majority 
of students $(75.5 \%)$ were in the second, third, and fourth grades and minorities were in the fifth and sixth grades (3.1 each). The highest frequency was for normal weight students $(50.8 \%)$ while overweight and obese students represent about $39 \%$.

Table 1: Personal data of studied students of Ain Shams University, Egypt, 2015-2016

\begin{tabular}{ll}
\hline Personal data & \\
\hline Age(years): & $17-26$ years \\
Minimum-Maximum & $20.3 \pm 1.5$ years \\
Mean \pm SD & \\
Gender (n=445): & $\mathrm{N}(\%)$ \\
Male & $181(40.7)$ \\
Female & $264(59.3)$ \\
Faculty (n=445): & $\mathrm{N}(\%)$ \\
Medicine & $101(22.7)$ \\
Others & $344(77.3)$ \\
Grade (n=445): & $\mathrm{N}(\%)$ \\
First & $81(18.20)$ \\
Second & $112(25.20)$ \\
Third & $97(21.80)$ \\
Fourth & $127(28.50)$ \\
Fifth & $14(3.15)$ \\
Sixth & $14(3.15)$ \\
BMI (kg/m2) (n=445): & $\mathrm{N}(\%)$ \\
Underweight & $45(10.1)$ \\
Normal & $226(50.8)$ \\
Overweight & $130(29.2)$ \\
Obese & $44(9.9)$ \\
Minimum-Maximum & $14.2-50.5$ \\
Mean \pm SD & $24.5 \pm 4.2$ \\
\hline
\end{tabular}

The frequency of DEA was $73.3 \%$ (326 students) as shown in Fig. 1

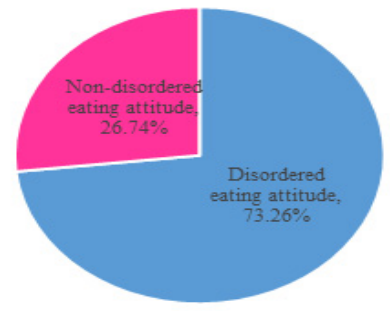

- Disordered eating attitude = Non-disordered eating attitude

Fig. 1: Frequency of disordered eating attitudes among the studied students of Ain Shams University, Egypt, 2015-2016.
There was no significant relation between presence of DEA and personal data of students such as age, sex, type of education, and BMI $(P>0.05)$ (Table 2).

Table 2: Relation between disordered eating attitude and personal characteristics of students of Ain Shams University, Egypt, 2015$2016(\mathrm{~N}=445)$

\begin{tabular}{|c|c|c|c|c|}
\hline Personal Data & $\begin{array}{c}\text { Non- } \\
\text { disorderd } \\
\text { eating } \\
\text { attitude } \\
\mathrm{N}(\%)\end{array}$ & $\begin{array}{l}\text { Disordered } \\
\text { eating } \\
\text { attitude } \\
\text { N }(\%)\end{array}$ & $\begin{array}{c}\text { Chi } \\
\text { Square } \\
\text { test }\end{array}$ & $\begin{array}{c}\mathrm{P} \\
\text { value }\end{array}$ \\
\hline \multicolumn{5}{|l|}{ Gender } \\
\hline Male & $55(30.4)$ & $126(69.6)$ & 2.07 & 0.15 \\
\hline Female & $64(24.2)$ & $200(75.8)$ & & \\
\hline \multicolumn{5}{|l|}{ Faculty } \\
\hline Medical & $21(20.8)$ & $80(79.2)$ & 2.36 & 0.12 \\
\hline Non-medical & $98(28.5)$ & $246(71.5)$ & & \\
\hline \multirow[t]{2}{*}{$\begin{array}{l}\text { BMI } \\
\text { Underweight } \\
\text { Normal } \\
\text { Overweight } \\
\text { Obese }\end{array}$} & $\begin{array}{l}19(42.2) \\
56(24.8) \\
34(26.2) \\
10(22.7)\end{array}$ & $\begin{array}{c}26(57.8) \\
170(75.2) \\
96(73.8) \\
34(77.3)\end{array}$ & 2.27 & 0.13 \\
\hline & Mean \pm SD & $\begin{array}{l}\text { Mean } \\
\pm \mathrm{SD}\end{array}$ & $\mathrm{t}$ test & $\begin{array}{c}\mathrm{p} \\
\text { value }\end{array}$ \\
\hline Age (years) & $20.1 \pm 1.5$ & $20.3 \pm 1.5$ & 1.15 & 0.25 \\
\hline
\end{tabular}

Personal, social, and environmental barriers to physical activity and healthy eating among the studied students are presented in Tables 3 and 4. Each barrier is classified as important barrier, somewhat important barrier, or not a barrier at all. 
Table 3: Perceived barriers to physical activity among studied students of Ain Shams University, Egypt, 2015-2016

\begin{tabular}{|c|c|c|c|}
\hline Barrier & $\begin{array}{c}\text { Imp. } \\
\text { N }(\%)\end{array}$ & $\begin{array}{c}\text { Som. } \\
\text { N }(\%)\end{array}$ & $\begin{array}{c}\text { Not. } \\
\text { N (\%) }\end{array}$ \\
\hline \multicolumn{4}{|l|}{ Personal barriers to physical activity: } \\
\hline Do not have the skills to do physical activity, exercise, or sport & $89(20)$ & $162(36.4)$ & $194(43.6)$ \\
\hline Not enjoying physical activity, exercise, or sport & $52(11.7)$ & $98(22)$ & $295(66.3)$ \\
\hline Do not have motivation to do physical activity, exercise, or sport & $42(9.4)$ & $184(41.4)$ & $219(49.2)$ \\
\hline \multicolumn{4}{|l|}{ Social support barriers to physical activity: } \\
\hline No Faculty staff' support to be physically active & $155(34.8)$ & $117(26.3)$ & $173(38.9)$ \\
\hline No friends' support to be physically active & $118(26.5)$ & $132(29.7)$ & $195(43.8)$ \\
\hline No parents' support to be physically active & $112(25.2)$ & $118(26.5)$ & $215(48.3)$ \\
\hline \multicolumn{4}{|l|}{ Environmental barriers to physical activity: } \\
\hline Not having the time to be physically active & $213(47.9)$ & $160(36)$ & $72(16.2)$ \\
\hline Not having access to places to do physical activity, exercise, and sport & $127(28.5)$ & $145(32.6)$ & $173(38.9)$ \\
\hline Not being able to practice physical activity due to cultural factors & $126(28.3)$ & $89(20)$ & $230(51.7)$ \\
\hline Not being able to find physical activity facilities that are inexpensive & $123(27.6)$ & $155(34.8)$ & $167(37.5)$ \\
\hline Do not have enough information about how to increase physical activity & $110(24.7)$ & $188(42.3)$ & $147(33)$ \\
\hline Feeling shy when practicing exercise outdoors & $94(21.1)$ & $114(25.6)$ & $237(53.3)$ \\
\hline Do not have enough money to enroll on physical activity club & $80(18)$ & $123(27.6)$ & $242(54.4)$ \\
\hline The climate is not suitable for practicing exercise & $62(13.9)$ & $148(33.3)$ & $235(52.8)$ \\
\hline
\end{tabular}

Imp.: important barrier, Som.: somewhat important, Not.: not a barrier.

Table 4: Perceived barriers to healthy eating among studied students

\begin{tabular}{|c|c|c|c|c|}
\hline Barriers & $\begin{array}{c}\text { Imp. } \\
\text { N (\%) }\end{array}$ & $\begin{array}{l}\text { Som. } \\
\text { N (\%) }\end{array}$ & $\begin{array}{c}\text { Not. } \\
\text { N (\%) }\end{array}$ & $\begin{array}{c}\text { Total } \\
\text { N (\%) }\end{array}$ \\
\hline \multicolumn{5}{|l|}{ Personal and environmental barriers to healthy eating: } \\
\hline Do not have enough information about a healthy diet & $115(25.8)$ & $206(46.3)$ & $124(27.9)$ & $445(100)$ \\
\hline Do not have motivation to eat a healthy diet & $90(20.2)$ & $140(31.5)$ & $215(48.3)$ & $445(100)$ \\
\hline Do not enjoy eating healthy foods & $107(24)$ & $154(34.6)$ & $184(41.4)$ & $445(100)$ \\
\hline Do not have skills to plan and shop for preparing or cooking healthy foods & $156(35)$ & $168(37.8)$ & $121(27.2)$ & $445(100)$ \\
\hline Do not have access to healthy foods & $181(40.7)$ & $140(31.4)$ & $124(27.9)$ & $445(100)$ \\
\hline Not able to buy healthy foods that are expensive & $64(14.4)$ & $131(29.4)$ & $250(56.2)$ & $445(100)$ \\
\hline \multicolumn{5}{|l|}{ Social barriers to healthy eating: } \\
\hline No parents' support to eat a healthy diet & $67(15)$ & $116(26.1)$ & $262(58.9)$ & $445(100)$ \\
\hline No friends' support to eat a healthy diet & $130(29.2)$ & $151(33.9)$ & $164(36.9)$ & $445(100)$ \\
\hline No Faculty staff' support to eat a healthy diet & $109(24.5)$ & $123(27.6)$ & $213(47.9)$ & $445(100)$ \\
\hline Not having time to prepare or eat healthy foods because of university commitment & $180(40.4)$ & $164(36.9)$ & $101(22.7)$ & $445(100)$ \\
\hline
\end{tabular}

Imp.: important barrier, Som.: somewhat important, Not.: not a barrier. 


\section{DISCUSSION}

Using the EAT-26 questionnaire, $73.3 \%$ of Ain Shams University students were defined as having DEAs. The prevalence of disordered eating attitudes in the current study was higher compared with other studies in Arabic countries as it was 31.8 and $33.6 \%$ among men and women in Kuwait ${ }^{[21]}$, and ranged from 13.8 to $47.3 \%$ among men, and from 16.2 to $42.7 \%$ among women in seven Arab countries $^{[17]}$. Also, the rate was higher compared with rates recorded in more developed countries such as Singapore: $10.5 \%{ }^{[22]}$, Turkey: $45.2 \%{ }^{[23]}$, and Spain: $7.8 \%{ }^{[24]}$. The prevalence of DEAs in the current study was high as our country is less socioeconomically developed compared with these countries. In addition, over-reporting in selfadministered tests cannot be excluded. This supports suggestions that obesity prevention efforts and getting knowledge about body weight and eating habits may be most warranted among lower socio-economic status (SES) groups $^{[25]}$

In the present study, female and male students had similar DEAs. In agreement with these results; Edman and Yates $^{[26]}$ reported no sex effect on EAT score. However, our results disagree with a study performed in Singapore ${ }^{[22]}$, Israel ${ }^{[27]}$, and in Jordan, Libya, Palestine, and Syria ${ }^{[16]}$ which showed that the female students had DEAs more than men. This variation in results is explained on the basis that rates of body dissatisfaction in men are rapidly approaching those of women especially for this age group. For men, body dissatisfaction is more commonly manifested as pursuit of a muscular, lean physique rather than a lower weight. Also, most of the common known risk factors for EDs apply to men and women like perfectionism, bullying, dieting, trauma, and childhood obesity ${ }^{[28]}$. Other factors may be involved, and interactions among these factors may exist that need further studies to verify these relations.

The mean BMI of students was $24.5 \pm 4.2$ based on the CDC standard weight status categories (BMI, 2014) and the prevalence of overweight and obesity in our study were 29.2 and $9.9 \%$, respectively. This finding was higher than that reported by a Chinese study (mean $20.6 \pm 2.2$ ) and overweight and obesity were 2.5 and $0.4 \%$ respectively ${ }^{[29]}$, and also higher than the prevalence of overweight and obesity in a Sudanese study by Al-Haj et al. ${ }^{[30]}$ (16.7 and 3.9\%, respectively). Our rates of overweight and obesity are close to the recent national figures revealed by the DHS, Egypt, 2014 as it shows that one-quarter of girls aged 5-19 years are overweight, and $10 \%$ are obese. The proportions of overweight boys $(25 \%)$ or obese $(11 \%)$ are very similar to the levels found among girls. Among girls, the proportion who are overweight or obese rises with age. The opposite pattern is observed for boys $^{[31]}$. This high frequency of overweight and obesity may be due to increasing consumption of high-calorie diets and shift of lifestyles toward sedentariness in our country.
There was no association between disturbed eating attitudes among university students and their weight Similar to our findings, BMI was not found to be correlated with EAT-26 score among Indian nursing students ${ }^{[32]}$. Not in agreement with our results Rouzitalab et al. ${ }^{[33]}$ mentioned that some anthropometric indices such as BMI and central obesity indices were related to the increase in DEAs. Similar rates of disturbed eating attitude in obese and nonobese students could be explained as attitude could be affected as a result of obesity or even fear of obesity in nonobese ones.

Also, there was no relation between EAT and type of faculty and age of the students. This is explained on the basis that the range of age was not wide so there is no clear effect of age. Also, all youth had this negative attitude regardless of the type of faculty as the main factors that affect DEA are related to peer pressure, social media, and fashion advertisement rather that their type of education.

Among the studied barriers to physical activities, lack of time was the most highlighted in our study. Similar outcomes can be found in studies carried out between university students in Egypt ${ }^{[34]}$, Saudi Arabia ${ }^{[35]}$, Kuwait $^{[36]}$, and also in Spain ${ }^{[37]}$. The university students who often spend more time away from home have a progressive increase in responsibilities, academic tasks, and thus it is difficult to allocate adequate time for the practice of physical activity alongside their studies, and social and family commitments.

Regarding social barriers to physical activity, lack of teacher support was reported by a high percent of students, followed by lack of friend and family support. Among personal barriers lack of skills was the most commonly reported one. This is noticed in our community as emphasis of families is focused on academic achievement rather than recreation and healthy behaviors and skills.

Among the studied personal and environmental barriers to healthy eating, lack of access to healthy foods was the first barrier reported by students. Also, lack of time to prepare or eat healthy foods because of university commitment was the most important social barrier in the current study. The most frequently available foods in university or schools are mostly junk food, snacks, and soft drinks rather than healthy food such as fruits, vegetables, or fresh juice.

\section{LIMITATIONS}

Some important limitations encountered in this study are worth mentioning. The sample, being a convenient sample, yielded unequal representation of students in the different faculties and in the different grades. A larger sample size would have been more appropriate given the diversity of the faculties studied. In addition, the inherent bias of self-reporting in self-administered tests cannot be overlooked. A more representative sample including more 
homogeneous groups of students and varieties of faculties would ensure better generalization of results.

\section{CONCLUSION}

There was a high prevalence of EAT among Ain Shams Male and Female University students, and there was no sex difference or effect of obesity on EAT prevalence. Lack of time was the most important barrier for practicing in physical activity and preparing a healthy meal reported by our sample. This necessitates more efforts to help the youth at this age to overcome and treat these barriers. Health promotion strategies that provide increased motivation, support, and skills to enable university students to shop healthy, quick, and inexpensive meals and to promote more time-efficient physical activity and provide accessible places to practice these activities in the university are highly needed. Additional strategies that recognize the ED behaviors among this vulnerable group are particularly required to modify and correct these poor attitudes.

\section{CONFLICT OF INTEREST}

There are no conflicts of interest.

\section{REFERENCES}

1. Chang YJ, Lin W, Wong Y. Survey on eating disorders-related thoughts, behaviours, and their relationship with food intake and nutritional status in female high school students in Taiwan. J Am Coll Nutr 2011; 30: 39-48.

2. Deshpande S, Basil MD, Basil DZ. Factors influencing healthy eating habits among college students: an application of the health belief model. Health Mark Q 2009; 26: 145-164.

3. Nelson MC, Story M, Larson NI, Neumark-Sztainer D, Lytle LA. Emerging adulthood and college-aged youth: an overlooked age for weight-related behavior change. Obesity 2008; 16: 2205-2211.

4. Rubina A, Shoukat S, Raza R, Shiekh MM, Rashid Q, Siddique MS, et al. Knowledge and practice of healthy lifestyle and dietary habits in medical and nonmedical students of Karachi, Pakistan. J Pak Med Assoc 2009; 59: 650-655.

5. Eapen V, Mobrouk AA, Bin-Othman S. Disordered eating attitudes and symptomatology among adolescent girls in the United Arab Emirates. Eat Behav 2006; 7: 53-60.

6. Smink FR, Hoeken VD, Hoek HW. Epidemiology of eating disorders: incidence, prevalence and mortality rates. Curr Psychiatry Rep 2012; 14: 406-414.

7. Campbell K, Peebles R. Eating disorders in children and adolescents: state of the art review. Pediatrics 2014; 134: 582-592.

8. American Psychological Association. Available at: http://www.apa.org/topics/eating/. [Accessed 11 January 2017]

9. Sajwani RA, Shoukat S, Raza R, Shiekh MM, Rashid Q, Siddique MS. Knowledge and practice of healthy lifestyle and dietary habits in medical and nonmedical students of Karachi, Pakistan. J Pak Med Assoc 2009; 59: 650-655.

10. Cullen KW, Hartstein J, Reynolds KD, Vu M, Resnicow K, Greene N, White MA. Improving the school food environment: results from a pilot study in middle schools. J Am Diet Assoc 2007; 107: 484-489.

11. Evans AE, Wilson DK, Buck J, Torbett H, Williams J. Outcome expectations, barriers and strategies for healthful eating: a perspective from adolescents from low-income families. Fam Community Health 2006; 29: 17-27.

12. Shepherd J, Harden A, Rees R, Brunton G, Garcia $\mathrm{J}$, Oliver S, et al. Young people and healthy eating: a systematic review of research on barriers and facilitators. Health Educ Res 2006; 21: 239-257.

13. Weinberg RS, Gould D. Foundation of sport and exercise psychology. 4th ed. Champaign, IL: Human Kinetics; 2007.

14. Musaiger A, Al-Mannai M, Tayyem R, Al-Lalla O, Ali E, Kalam F, et al. Perceived barriers to healthy eating and physical activity among adolescents in seven Arab countries: a cross-cultural study. Sci World J 2013; 2013: 11.

15. Garner DM, Olmsted MP, Bohr Y, Garfinkel PE. The Eating Attitudes Test: Psychometric features and clinical correlates. Psychol Med 1982; 12:871-878.

16. Al-Subaie A, Al-Shammari S, Bamgbove E, AlSabhan K, Al-Shehri S, Bennah AR. Validity of the Arabic version of the eating attitudes test. J Eat Disord 1996; 20: 321-324. 
17. Musaiger AO, Al-Mannai M, Tayyem R, Al-Lalla O, Ali EY, Kalam F, et al. Risk of disordered eating attitudes among adolescents in seven Arab countries by gender and obesity: a cross-cultural study. Appetite 2013; 60: 162-167.

18. Al-Subaie AS. Some correlates of dieting behavior in Saudi schoolgirls. Int J Eat Disord 2000; 28: 242-246.

19. Thomas J, Khan S, Abdulrahman AA. Eating attitudes and body image concerns among female university students in the United Arab Emirates. Appetite 2010; 54: 595-598.

20. WHO. Physical status: the use and interpretation of anthropometry. Report of a WHO Expert Committee. WHO Technical Report Series 854. Geneva, Switzerland: World Health Organization; 1995.

21. Musaiger AO, Al-Kandari FI, Al-Mannai M, Al-Faraj AM, Bouriki FA, Shehab FS, et al. Disordered eating attitudes among University students in Kuwait: the role of gender and obesity. Int J Prev Med 2016; 7: 67.

22. Ho TF, Tai BC, Lee EL, Cheng S, Liow PH. Prevalence and profile of females at risk of eating disorders in Singapore. Singapore Med J 2006; 47: 499-503.

23. Bas M, Karabudak E, Kiziltan G. Vegetarianism and eating disorders: association between eating attitudes and other psychological factors among Turkish adolescents. Appetite 2005; 44: 309-315.

24. Rodriguez-Cano T, Beato-Fernandez L, BelmonteLlario A. New contributions to the prevalence of eating disorders in Spanish adolescents: detection of false negatives. Eur Psychiatry 2005; 20: 173-178.

25. Gibbons P. The relationship between eating disorders and socioeconomic status: It's not what you think. Nutrition Noteworthy 2001; 4:1. https://escholarship. org/uc/uclabiolchem_nutritionnoteworthy

26. Edman JL, Yates A. Eating attitudes among college students in Malaysia: an ethnic and gender comparison. Eur Eat Disord Rev 2004; 12: 190-196.

27. Greenberg L, Cwikel J, Mirsky J. Cultural correlates of eating attitudes: a comparison between native-born and immigrant university students in Israel. Intl J Eat Disord 2007; 40: 51-58.

28. Eating Disorders in Males. Available at: http://www. nedc.com.au/eating-disorders-in-males [Accessed 14 February 2017]

29. Sakamaki R, Toyama K, Amamoto R, Liu CJ, Shinfuku N. Nutritional knowledge, food habits and health attitude of Chinese university students: a cross sectional study. Nutr J 2005; 4: 1475-1489.

30. Al-Haj MEA, Awooda HA, Elnimeiri MKM. Eating habits among medical students in a Sudanese medical faculty. Int J Med Sci 2015; 3: 64-69.

31. Ministry of Health and Population [Egypt], El-Zanaty and Associates [Egypt], and ICF International. Egypt Demographic and Health Survey 2014. Cairo, Egypt and Rockville, Maryland, USA: Ministry of Health and Population and ICF International; 2015.

32. Balhara YP, Mathur S, Kataria DK. Body shape and eating attitudes among female nursing students in India. East Asian Arch Psychiatry 2012; 22: 70-74.

33. Rouzitalab T, Gargari PB, Amirsasan R, Jafarabadi MA, Naeimi AF, Sanoobar M. The relationship of disordered eating attitudes with body composition and anthropometric indices in physical education students. Iran Red Crescent Med J 2015; 17 : 11.

34. El-Gilany AH, Badawi K, El-Khawaga G, Awadalla N. Physical activity profile of students in Mansoura University. East Mediterr Health J 2011; 17: 694-702.

35. Gawwad ES. Stages of change in physical activity, self-efficacy and decisional balance among Saudi university students. J Family Community Med 2008; 15: 107-115.

36. Andajani-Sutjahjo $\mathrm{S}$, Ball $\mathrm{K}$, Warren $\mathrm{N}$, Inglis V, Crawford D. Perceived personal, social and environmental barriers to weight maintenance among young women: a community survey. Int J Behav Nutr Phys Act 2004; 1:15. 37. Gómez M, Gallegos AG, Extremera AB. Perceived barriers by university students in the practice of physical activities. J Sports Sci Med 2010; 9: 374-381. 